\title{
South Africa's vital statistics are currently not suitable for monitoring progress towards injury and violence Sustainable Development Goals
}

Two of the most important targets to achieving the United Nation's Sustainable Development Goals (SDGs) for reducing violence and other injuries are Target 3.6: to 'halve the number of global deaths and injuries from road traffic accidents' by 2020; and Target 16.1: the significant reduction of 'all forms of violence and related death rates everywhere. ${ }^{[1]}$ Police statistics on homicide, and transport deaths from the Road Traffic Management Corporation, are considered to be under-reported ${ }^{[2]}$ and are not a reliable source for monitoring SDGs.

In South Africa (SA), vital statistics data are the only routine source that captures unnatural and natural deaths through death registration. Since the early 1990s, focused initiatives have identified and addressed deficiencies in the completeness of death registration ${ }^{[3-5]}$ and recent estimates indicate that completeness for persons aged $\geq 2$ years is $>90 \% .{ }^{[6]}$ However, there are still concerns about the quality of data relating to the cause of death, i.e. underreporting of HIV/AIDS deaths owing to misclassification to other causes, ${ }^{[7-10]}$ a large proportion of deaths with ill-defined causes, ${ }^{[1]}$ and the validity of single-cause data. ${ }^{[12]}$

The misclassification of injury deaths is another major limitation. ${ }^{[2,13]}$ The Inquest Act of $1959^{[14]}$ precludes forensic pathologists from reporting the manner of death, i.e. whether it is due to homicide, suicide, transport or other unintentional injuries, on the basis that it may prejudice the findings of the inquest. In many cases, only the nature of injury, e.g. penetrating wound, and whether the death is natural or unnatural, is reported on the death notification form. As the International Statistical Classification of Diseases and Related Health Problems 10th Revision (ICD-10) ${ }^{[15]}$ coding convention demands that injury deaths with unknown intent default to unintentional, the reported gunshot injuries without stated intent are all coded to unintentional gunshot injuries. ${ }^{[16]}$ Strict application of the ICD-10 coding rules has resulted in 89 99\% of gunshot deaths being reported as unintentional from 2007 onward. ${ }^{[17]}$ Homicides are therefore grossly under-represented in official vital statistics.

The misclassification of injury deaths was clearly demonstrated in a nationally representative study of injury deaths presenting to state forensic mortuaries in 2009. ${ }^{[18]}$ Statistics SA (Stats SA) classified nearly two-thirds $(63.9 \%)$ of injury deaths as being due to 'other external causes of accidental injury' (Fig. 1), with $10.3 \%$ due to homicide and $11.5 \%$ caused by transport injuries. ${ }^{[16]}$ In contrast, the mortuary study demonstrated that homicide accounted for $36.2 \%$ of all unnatural deaths and transport for $33.8 \%$. Moreover, the total number of injury deaths estimated from our study ( $N=52493)$ is higher than the number reported by Stats SA ( $N=49456)$, possibly because a number of deaths are registered before the completion of the investigation (to enable burial). Cases that are reported to be under investigation at the time of registration are coded to natural causes. Once the inquest into an unnatural death is complete, the civil registration system does not provide a mechanism for Stats SA to update the manner of death.

In the 2014 Stats SA cause-of-death data, despite a slight decrease in other unintentional injury deaths to $58.1 \%,{ }^{[19]}$ the problem of misclassification of homicide and transport deaths to other unintentional injuries remains. Vital statistics cause-ofdeath data for injuries in SA are inaccurate and misleading and cannot be used to monitor progress on achieving the SDGs by 2030. The absence of information on the manner of injury death in the official statistics needs to be addressed urgently. A review and possible amendment of the Inquest Act would possibly take years. We strongly recommend that the death notification form (DHA-1663) be amended in line with the updated World Health Organization's recommendation, ${ }^{[15]}$ to include a stand-alone field for information about the manner of injury death for unnatural causes. We suggest that forensic pathologists record the alleged manner of death when they are uncertain, which can include a proviso stating that such information is for statistical purposes only. This matter is currently being discussed with stakeholders, including the National Forensic Pathology Committee, legal advisers to the departments of Home Affairs and Health, and Stats SA - holding a promise for injury data to conform to international standards, which will go a long way towards monitoring violence and injury indicators for the SDGs.

A
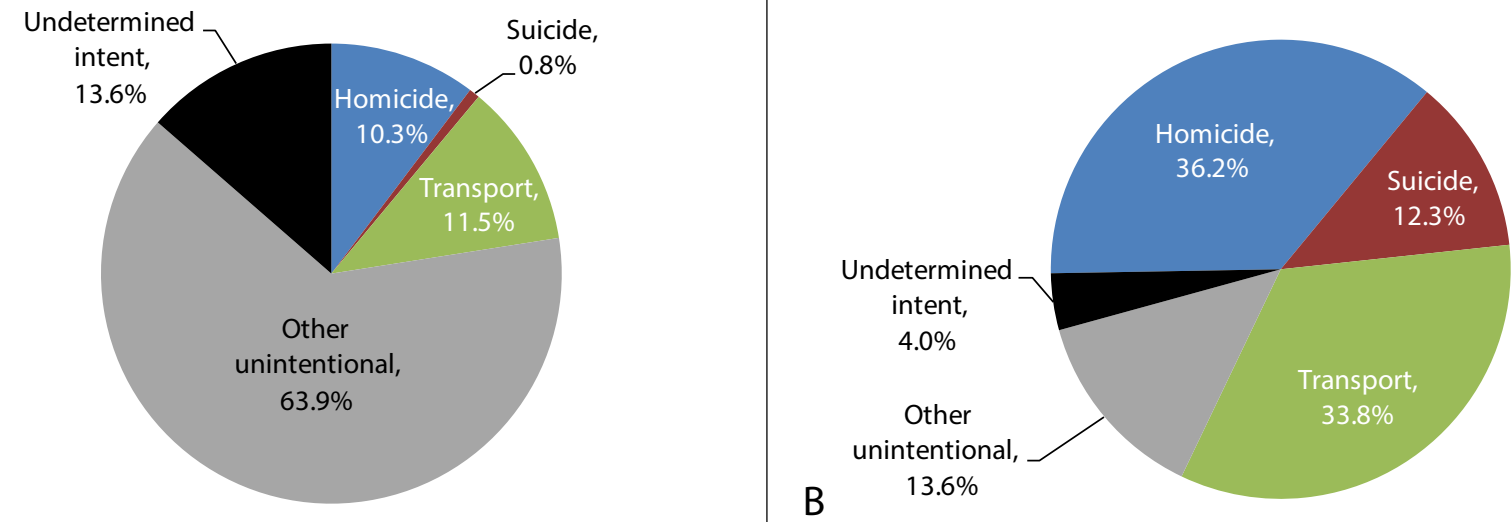

Fig. 1. Manner of injury death. (A) Stats SA, $2009\left(\mathrm{~N}=49\right.$ 456); ${ }^{[16]}$ and (B) IMS, $2009\left(\mathrm{~N}=52\right.$ 493). ${ }^{[18]}$ Stats SA categories are grouped according to IMS. (Stats SA = Statistics SA; IMS = Injury Mortality Survey.) 


\section{Prinsloo, D Bradshaw, J Joubert}

South African Medical Research Council, Burden of Disease Research Unit, Cape Town, South Africa

megan.prinsloo@mrc.ac.za

\section{R Matzopoulos}

South African Medical Research Council, Burden of Disease Research Unit, Cape Town; and School of Public Health and Family Medicine, Faculty of Health Sciences, University of Cape Town, South Africa

\section{P Groenewald}

South African Medical Research Council, Burden of Disease Research Unit, Cape Town, South Africa

1. United Nations. Transforming our world: The 2030 agenda for sustainable development. 2015. http:// www.un.org/ga/search/view_doc.asp?symbol=A/RES/70/1\&Lang=E (accessed 4 March 2017).

2. Matzopoulos R, Prinsloo M, Pillay-van Wyk V, et al. Injury-related mortality in South Africa: A retrospective descriptive study of post-mortem investigations. Bull World Health Organ 2015;93:303-313. http://dx.doi.org/10.2471/BLT.14.145771

3. Dorrington RE, Moultrie TA, Timæus IM. Estimation of Mortality Using the South African Census 2001 Data. Cape Town: Centre for Actuarial Research, University of Cape Town, 2004. http://www. commerce.uct.ac.za/Research_Units/CARE/Monograph/Monographs/Monol 1.pdf (accessed 21 April 2017).

4. Dorrington RE, Bourne D, Bradshaw D, Laubscher R, Timæus IM. The Impact of HIV/AIDS on Adult Mortality in South Africa. Cape Town: South African Medical Research Council, 2001. http://www. mrc.ac.za/bod/complete.pdf (accessed 21 April 2017)

5. Bradshaw D, Kielkowski D, Sitas F. New birth and death registration forms - A foundation for the future, a challenge for health workers? S Afr Med J 1998;88(8):971-974.
6. Dorrington RE, Bradshaw D, Laubcsher R, Nannan N. Rapid Mortality Surveillance Report, Dorrington RE, Bradshaw D, Laubcsher R, Nannan N. Rapid Mortality Surveillance Report,
2014. Cape Town: South African Medical Research Council, 2015. http://www.mrc.ac.za/bod/ RapidMortalitySurveillanceReport2014.pdf (accessed 21 April 2017).

7. Bradshaw D, Groenewald P, Laubscher R, et al. Initial burden of disease estimates for South Africa, 2000. S Afr Med J 2003;93(9):682-688.

8. Yudkin PL, Burger EH, Bradshaw D, Groenewald P, Ward AM, Volmink J. Deaths caused by HIV disease under-reported in South Africa. AIDS 2009;23(12):1600-1602. http://dx.doi.org/10.1097/ QAD.0b013e32832d 4719

9. Burger EH, Groenewald P, Bradshaw D, Ward AM, Yudkin PL, Volmink J. Validation study of cause of death statistics in Cape Town, South Africa, found poor agreement. J Clin Epidemiol 2012;65(3):309-316. http://dx.doi.org/10.1016/j.jclinepi.2011.08.007

10. Westwood AT. Childhood deaths due to HIV - the role of the new death certificate. S Afr Med J 2000;90(9):877.

11. Pillay-van Wyk V, Bradshaw D, Groenewald P, Laubscher R. Improving the quality of medical certification of cause of death: The time is now! S Afr Med J 2011;101(9):626.

12. Joubert J, Rao C, Bradshaw D, Vos T, Lopez AD. Evaluating the quality of national mortality statistics from civil registration in South Africa, 1997 - 2007. PLoS ONE 2013;8(5):e64592. http://dx.doi.org/10.1371/
fortics journal.pone.0064592

13. Groenewald P, Bradshaw D, Neethling I, et al. Linking mortuary data improves vital statistics on cause of death of children under five years in the Western Cape Province of South Africa. Trop Med Int Health 2016;21(1):114-121. http://dx.doi.org/10.1111/tmi.1262

14. South Africa. Inquest Act No. 58 of 1959.

15. World Health Organization. International Statistical Classification of Diseases and Related Health Problems, 10th Revision, Version for 2016. Geneva: WHO, 2016. http://apps.who.int/classifications/ icd10/browse/2016/en (accessed 9 March 2017).

16. Statistics South Africa. Mortality and Causes of Death in South Africa, 2009: Findings from Death Notification. Pretoria: Stats SA, 2011.

17. Matzopoulos R, Groenewald P, Abrahams N, et al. Where have all the gun deaths gone? S Afr Med J 2016;106(6):589-591. http://dx.doi.org/10.7196/SAMJ.2016.v106i6.10379

18. Matzopoulos R, Prinsloo M, Bradshaw D, et al. The Injury Mortality Survey: A National Study of Injury Mortality Levels and Causes in South Africa in 2009. Cape Town: Medical Research Council, 2013.

19. Statistics South Africa. Mortality and Causes of Death in South Africa, 2014: Findings from Death Notification. Pretoria: Stats SA, 2015

S Afr Med J 2017;107(6):470-471. DOI:10.7196/SAMJ.2017.v107i6.12464 